\title{
Bismuth-indium system: thermodynamic properties of liquid alloys
}

\author{
T. Kulikova*, A. Mayorova, A. Shubin, V. Bykov, K. Shunyaev \\ Institute of Metallurgy UB RAS, Amundsena st. 101, Ekaterinburg 620016, Russia
}

Received 8 July 2014, received in revised form 27 September 2014, accepted 21 October 2014

\begin{abstract}
The thermodynamic activities, the excess integral and partial Gibbs energies, and the enthalpy of mixing for Bi-In melts were studied. For investigation, the methodology of thermodynamic modeling (TM) including the models of an ideal solution (IS) and an ideal solution of interaction products (ISIP) was applied. The modeling was performed for the pressure of $0.1 \mathrm{MPa}$ in an argon atmosphere. The temperature and concentration ranges of study comply with liquid phase region on the Bi-In phase diagram. It has been established the thermodynamic properties of Bi-In melts show negative deviations from Raoult's law. The mixing enthalpy minimum was observed at $x(\mathrm{In})=0.55$ and $\Delta H^{\mathrm{E}}=-1.33 \mathrm{~kJ} \mathrm{~mol}^{-1}$. In the present study, the lowest values of the excess integral Gibbs free energy were determined as -1.80 and $-1.99 \mathrm{~kJ} \mathrm{~mol}^{-1}$ at the temperatures 600 and $873 \mathrm{~K}$, respectively.
\end{abstract}

K e y w or d s: Bi-In system, melt, enthalpy of mixing, activity, Gibbs energy, associates

\section{Introduction}

To calculate the equilibrium compositions and thermodynamic properties of the metallic melts characterized by strong interactions between atoms of their components that lead to the formation of associates or clusters, one can use particularly suitable models that take into account the chemical equilibrium between the associates and atoms of constitutive elements present in alloy melts. The specific details of liquid metallic melt structure are concerned in the basic assumptions of an ideal and regular associated solution models.

These models enable us to describe the thermodynamic functions taking into account the existence of short range order phenomena in metallic melts that is often indicated by a pronounced asymmetry of the corresponding curves describing concentration dependences [1-10].

The majority of existing models offer direct ways of properties calculation, which are complicated or even impossible to realize for binary and multi-component systems. Some adjustable parameters are required to perform the calculations. Estimation of these parameters is the real challenge task.
In the present work the model of the "ideal solution of interaction products" (ISIP) was applied. This approach is original modification of the ideal associated solutions model proposed by Prigogine and Defay [1].

According to our model the composition of the associates is identical with the really existing intermetallic compounds in the system under investigation. The content of each associate in the solution depends on both the equilibrium state of all the hetero-phase system at specified parameters (e.g., pressure $P$ and temperature $T$ ) and initial composition.

The ISIP model was applied earlier to determine the composition of multi-component metallic solutions and their thermodynamic properties: components activities and excess thermodynamic functions (including the integral thermodynamic properties of the melts) $[11,12]$.

In the present work the thermodynamic properties of Bi-In system were studied by ISIP method. The Bi-In system has attracted much attention due to its wide technical application. Indium, bismuth and their alloys are applied as the heat transfer agents, soft solders and protective coatings [13]. The In-Bi alloys have been also used as subsystem of lead free solders (including diffusive-hardening compositions like $\mathrm{Cu}$ -

*Corresponding author: tel.: +7 34323290 36; fax: +7 34326791 86; e-mail address: kuliko@gmail.com 
Table 1. Thermochemical properties of solid phases of the Bi-In system

\begin{tabular}{ccccc}
\hline & $\Delta_{\mathrm{f}} H^{\circ}\left(\mathrm{kJ} \mathrm{mol}^{-1}\right)$ & $\Delta_{\mathrm{f}} S\left(\mathrm{~J} \mathrm{~mol}^{-1} \mathrm{~K}^{-1}\right)$ & $T_{\text {fusion }}(\mathrm{K})[21]$ & $\Delta H_{\text {fusion }}\left(\mathrm{kJ} \mathrm{mol}^{-1}\right)$ \\
\hline $\mathrm{Bi}_{1} \mathrm{In}_{1}$ & $-0.73[21,24],-0.75[25],-2.98[22]$ & 3.79 & 389.0 & $7.30[23,24], 7.32[26]$ \\
$\mathrm{Bi}_{3} \mathrm{In}_{5}$ & $-0.54[21,24],-1.69[22]$ & 4.12 & 361.9 & $6.49[23,24]$ \\
$\mathrm{Bi}_{1} \mathrm{In}_{2}$ & $-0.48[12,17],-0.50[25],-0.46[22]$ & 4.19 & 362.5 & $4.60[23,24]$ \\
\hline
\end{tabular}

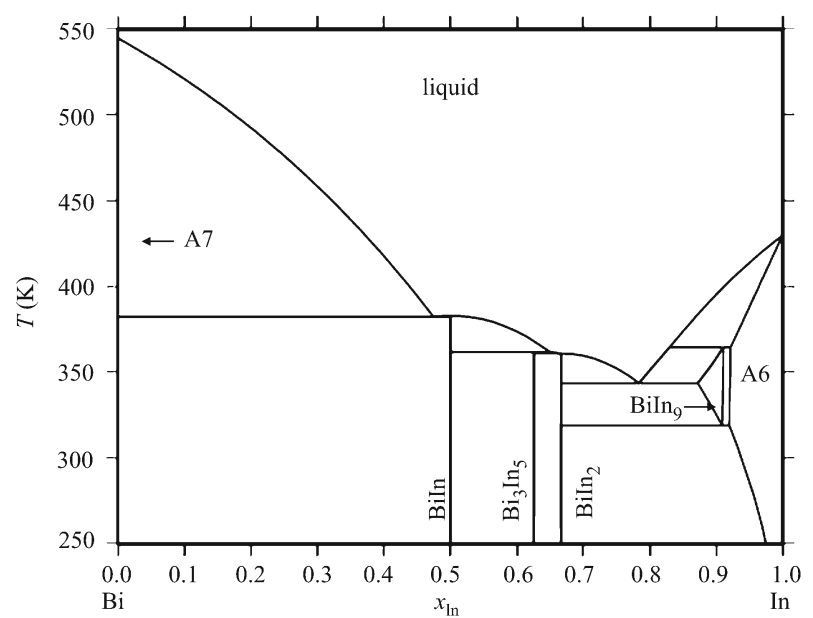

Fig. 1. Phase diagram for the system Bi-In [21].

Ga-In-Bi). The last mentioned alloys exhibit complex multi-phase structures. $\mathrm{Bi}$ is the component which can harden $\mathrm{Cu}-\mathrm{Ga}-\mathrm{In}$ system and essentially improve its exploitation properties.

Besides we have large experimental and calculated data sets on the thermodynamic properties of the Bi-In system [14-16]. These data were obtained mainly in $1970-80$-s. It is of interest to compare the data mentioned with the results of our methods and approaches and to refine available thermodynamic information.

So, the present work aims to investigate thermochemical properties of the equilibrium phases and also to describe the structure (set of associates) for In-Bi melts by the method of thermodynamic modeling using the ISIP approach.

\section{Theoretical study}

The Bi-In phase diagram has been first assessed by Hansen and Anderko [17]. These authors reported the existence of the BiIn and $\mathrm{BiIn}_{2}$ intermetallics in the Bi-In system. Further, the Bi-In phase diagram was reassessed taking into account the studies of the Bi-In system by DTA and X-ray techniques as well as by measuring the superconductive state transition temperature [18-20] (Fig. 1).

It was established that three intermediate phases exist in the Bi-In system. These phases have narrow homogeneity ranges and are approximated by the compositions of the $\mathrm{BiIn}, \mathrm{Bi}_{3} \mathrm{In}_{5}, \mathrm{BiIn}_{2}$ stoichiometric compounds. The intermetallics BiIn and $\mathrm{BiIn}_{2}$ are melted congruently at $383 \mathrm{~K}$ [19] and $363 \mathrm{~K}$ [21], respectively. The $\mathrm{Bi}_{3} \mathrm{In}_{5}$ phase observed in the works [19-22] is formed by peritectic reaction at $362 \mathrm{~K}$. According to [14], $\mathrm{Bi}_{3} \mathrm{In}_{5}$ intermetallic is melted congruently. The fourth intermetallic compound ( $\alpha_{1}$-phase) with wide homogeneity region is formed by the peritectic reaction lower than $365.5 \mathrm{~K}$ and then decomposes at $322 \mathrm{~K}$ [19]. The stoichiometry of this phase is not well-defined; most of authors identify it as BiIn 9 intermetallic $[13,17]$. The experimental and calculated thermodynamic data of the solid and liquid phases are reported in references $[16,23]$.

The available data allow us to conclude that all phases in Bi-In system are determined. Most of the intermetallic compounds have a narrow homogeneity [21] and show the composition close to the stoichiometry formulae. Therefore we selected the most clearly defined phases $[21,16,23]$ which have following formulae: $\mathrm{BiIn}, \mathrm{Bi}_{3} \mathrm{In}_{5}, \mathrm{BiIn}_{2}$. According to the ISIP method, we assumed that the associates with the same stoichiometry could exist in liquid bismuth-indium alloys. Further, we performed the analysis of the primary experimental information for the intermetallic compounds mentioned above. The primary experimental information is required for thermodynamic modeling. These data are given in Table 1 [24$26]$.

Further, thermodynamic properties for Bi-In system (Table 1) were entered into the database (DB) of the program system HSC 6.1 in order to carry out the calculation procedures of thermodynamic modeling. The assumption concerning existence of the associates of the predefined composition allowed us to find the concentration and temperature dependences of thermodynamic functions of mixing [27].

In order to investigate the properties of Bi-In melt we used the ISIP model mentioned above [11, 12]. According to this approach the initial metallic system $(\mathrm{A}+\mathrm{B})$ with strong components interaction forms the liquid melt consisting of the atoms of the $[\mathrm{A}]$ and $[\mathrm{B}]$ components and also of the $\left[\mathrm{A}_{x} \mathrm{~B}_{y}\right]$ associates which correspond to actually existing intermetallics. It is important assumption that the thermodynamic functions of the $\left[\mathrm{A}_{x} \mathrm{~B}_{y}\right]$ associates (clusters) in the melt 


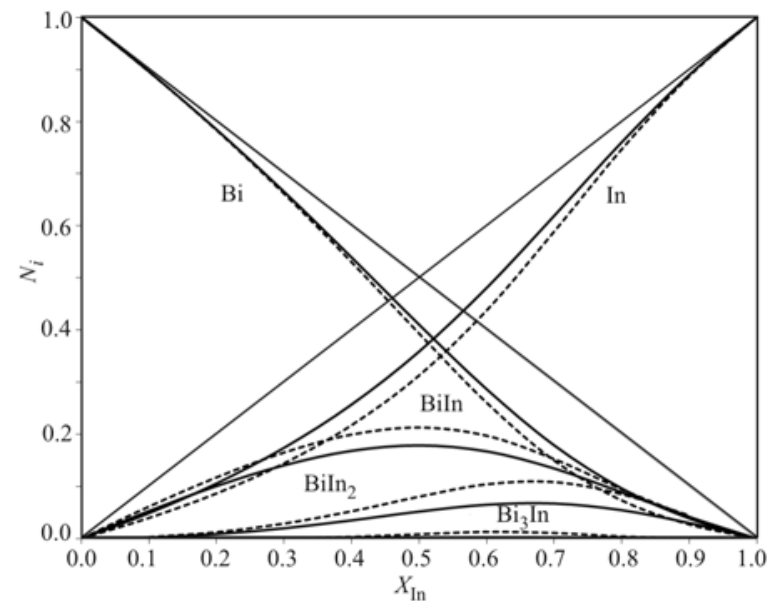

Fig. 2. Equilibrium numbers of associates BiIn, BiIn 2 and $\mathrm{Bi}_{3} \mathrm{In}_{5}$ together with unassociated $\mathrm{Bi}$ and $\mathrm{In}$ atoms in $\mathrm{Bi}-\mathrm{In}$ melts at $600(---)$ and $900 \mathrm{~K}(-)$.

are equal to those for the intermetallic compounds of the same composition at the temperature of the melt. The heats of mixing between $[\mathrm{A}],[\mathrm{B}]$ components and $\left[\mathrm{A}_{x} \mathrm{~B}_{y}\right]$ clusters are assumed to be zero. The entropies of mixing are calculated as well as for the ideal solutions [28]. So, we have included to the model of melt the $[\mathrm{BiIn}],\left[\mathrm{BiIn}{ }_{2}\right]$, and $\left[\mathrm{Bi}_{3} \mathrm{In}_{5}\right]$ associates that conditionally match to the stoichiometrically determined phases in the Bi-In system [9] (Fig. 1, Table 1).

\section{Results and discussion}

The composition of melts and gas phase of the BiIn system were studied at the pressure $0.1 \mathrm{MPa}$ in the temperature range $600-3500 \mathrm{~K}$ within the concentration range $\left(0 \leq x_{\text {In }} \leq 1\right.$, where $x_{\text {In }}$ is the content of indium, molar fraction, the balance $\mathrm{Bi}$ ). In the present study the thermodynamic modeling was performed by the program system HSC 6.1 and IS and ISIP models were applied.

The curves describing concentration dependences of the associates $\left(x_{i}\right)$ for Bi-In melts (Fig. 2) show the equilibrium numbers of associates in term of In content at 600 and $900 \mathrm{~K}$. One can see that the higher the total In content $x_{\text {In }}$, the greater is the concentration of "free" In atoms, and the lower is the concentration of "free" Bi atoms. Non monotonous concentration dependences were observed for all the $\left[\mathrm{Bi}_{x} \operatorname{In}_{y}\right]$ associates.

The maximum concentration of the specified cluster corresponds to the same intermetallic composition in the phase diagram Bi-In. The numerical value of the $\mathrm{Bi}_{3} \mathrm{In}_{5}$ associate concentration is the lowest compared to other clusters due to this associate has more atoms and its formation is accompanied by a signific-

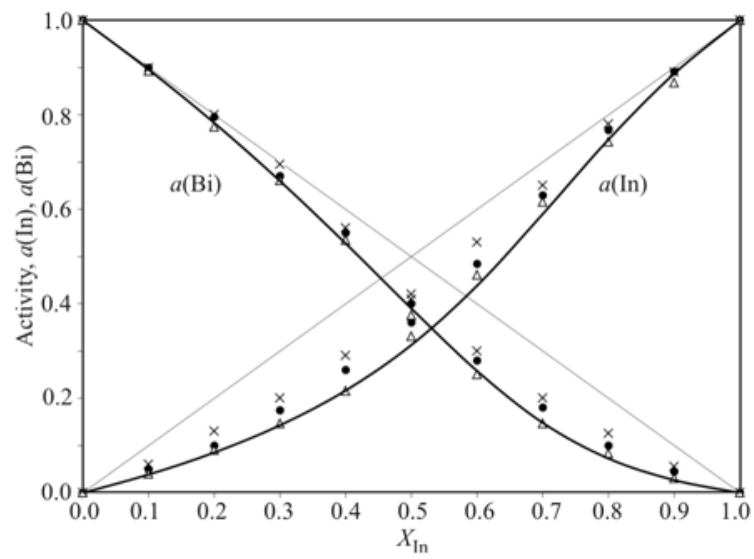

Fig. 3. Bismuth and indium activities in liquid alloys: this work (-) at $750 \mathrm{~K} ;[21]-\Delta$ at $673 \mathrm{~K} ;[16]-\bullet$ at $900 \mathrm{~K}$; $[22]-\times$ at $1100 \mathrm{~K}$.

ant entropy decrease. This prevents formation of such an associate at the temperature higher than $600 \mathrm{~K}$. Besides, the higher the temperature, the lower are the values of associates concentrations, and the higher are the concentrations of "pure" components Bi and In.

Hence it follows that temperature increase provides decomposition of $\left[\mathrm{Bi}_{x} \mathrm{In}_{y}\right]$ clusters. According to the ideal associated solutions model, the components activities are equal to their molar fraction in the melt, i.e. $a_{j} \equiv\left[N_{j}\right]$. As can be seen in Fig. 3 the $\mathrm{Bi}$ and In activities demonstrate significant deviations from the Raoult's law.

This fact is caused by the clusters formation in Bi-In melts. Good agreement of our calculated data concerning indium activity $\left(a_{\mathrm{In}}\right)$ and the results of the experimental works $[16,21,29]$ can be seen from the way in which the curves cross (Fig. 3). The calculated and experimental [14] concentration dependences of the excess mixing enthalpy $\left(\Delta H^{\mathrm{E}}\right)$ at $T=900 \mathrm{~K}$ are presented in Fig. 4.

The excess enthalpy of mixing was calculated by the equation:

$$
\Delta H^{\mathrm{E}}=H_{\mathrm{ISIP}}-H_{\mathrm{IS}},
$$

where $H_{\text {ISIP }}$ is the enthalpy of liquid system found by ISIP approximation and $H_{\text {IS }}$ is the enthalpy of the same system obtained for ideal solution Bi-In. The semi-empirical model [30] was used to estimate the enthalpies of mixing and compare them to our values and experimental data.

It can be seen that calculated and experimental values of integral enthalpy are negative $\left(\Delta H_{\text {int }}<0\right)$. Consequently, the Bi-In melt formation occurs with the heat release. This fact agrees with the negative deviations from the Raoult's law. The location of the integral mixing enthalpy minimum displaced to the indium-rich region for all three curves is shown in 
Table 2. Excess partial $\left(G_{\mathrm{Bi}}^{\mathrm{E}}, G_{\mathrm{In}}^{\mathrm{E}}\right)$ and integral $\left(-G^{\mathrm{E}}\right)$ Gibbs energies for Bi-In melts

\begin{tabular}{|c|c|c|c|c|c|c|c|c|}
\hline $\begin{array}{c}x_{\text {In }} \\
\text { molar } \\
\text { fractions }\end{array}$ & $\begin{array}{c}-G_{\mathrm{Bi}}^{\mathrm{E}}(600 \mathrm{~K}) \\
\left(\mathrm{kJ} \mathrm{mol}^{-1}\right) \\
{[21]}\end{array}$ & $\begin{array}{c}-G_{\mathrm{Bi}}^{\mathrm{E}}(600 \mathrm{~K}) \\
\left(\mathrm{kJ} \mathrm{mol}^{-1}\right) \\
{[\text { this work }]}\end{array}$ & $\begin{array}{c}-G_{\mathrm{In}}^{\mathrm{E}}(600 \mathrm{~K}) \\
\left(\mathrm{kJ} \mathrm{mol}^{-1}\right) \\
{[21]}\end{array}$ & $\begin{array}{c}-G_{\mathrm{In}}^{\mathrm{E}}(600 \mathrm{~K}) \\
\left(\mathrm{kJ} \mathrm{mol}^{-1}\right) \\
{[\text { this work] }}\end{array}$ & $\begin{array}{c}-G^{\mathrm{E}}(600 \mathrm{~K}) \\
\left(\mathrm{kJ} \mathrm{mol}^{-1}\right) \\
{[21]}\end{array}$ & $\begin{array}{c}-G^{\mathrm{E}}(600 \mathrm{~K}) \\
\left(\mathrm{kJ} \mathrm{mol}^{-1}\right) \\
\text { [this work] }\end{array}$ & $\begin{array}{c}-G^{\mathrm{E}}(873 \mathrm{~K}) \\
\left(\mathrm{kJ} \mathrm{mol}^{-1}\right) \\
{[16]}\end{array}$ & $\begin{array}{c}-G^{\mathrm{E}}(873 \mathrm{~K}) \\
\left(\mathrm{kJ} \mathrm{mol}^{-1}\right) \\
{[\text { this work] }}\end{array}$ \\
\hline 0.10 & 0.02 & 0.02 & 5.57 & 4.63 & 0.58 & 0.48 & 0.53 & 0.57 \\
\hline 0.20 & 0.17 & 0.10 & 4.77 & 4.18 & 1.09 & 0.92 & 1.01 & 1.07 \\
\hline 0.30 & 0.49 & 0.28 & 3.83 & 3.65 & 1.49 & 1.29 & 1.44 & 1.49 \\
\hline 0.40 & 0.98 & 0.61 & 2.92 & 3.04 & 1.75 & 1.58 & 1.80 & 1.80 \\
\hline 0.50 & 1.62 & 1.19 & 2.13 & 2.34 & 1.88 & 1.77 & 1.99 & 1.98 \\
\hline 0.60 & 2.43 & 2.14 & 1.47 & 1.57 & 1.85 & 1.80 & 1.95 & 1.99 \\
\hline 0.70 & 3.44 & 3.47 & 0.93 & 0.86 & 1.68 & 1.64 & 1.76 & 1.80 \\
\hline 0.80 & 4.79 & 5.02 & -0.057 & 0.34 & 1.34 & 1.28 & 1.36 & 1.40 \\
\hline 0.90 & 6.73 & 6.52 & -0.020 & 0.07 & 0.80 & 0.72 & 0.9 & 0.79 \\
\hline
\end{tabular}

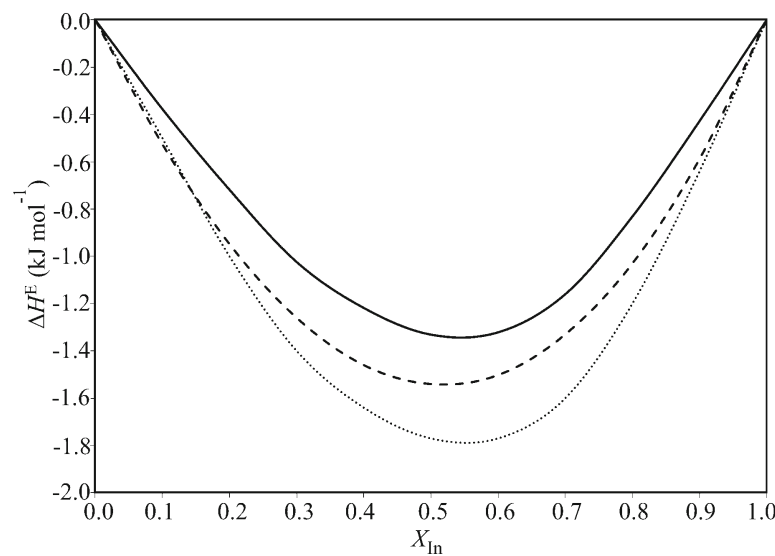

Fig. 4. Concentration dependences of the excess enthalpy of mixing $\Delta H^{\mathrm{E}}$ : this work $(-)$ at $900 \mathrm{~K} ;[23]-(---)$ at $900 \mathrm{~K} ;[29]-(\cdots)$ at $900 \mathrm{~K}$.

Fig. 4. According to the phase diagram (Fig. 1) all intermetallic phases for Bi-In system are located within the concentration range $x_{\text {In }}=0.5-0.95$. This fact confirms our assumption about the formation of associates with the same composition in Bi-In melt. The numeric values are also in satisfactory agreement. For example, for $x(\operatorname{In})=0.55: \Delta H_{\text {int }}$ (calculated) is equal to $-1.33 \mathrm{~kJ} \mathrm{~mol}^{-1}$, calculation by the method [30] gives $\Delta H_{\mathrm{int}}=-1.54 \mathrm{~kJ} \mathrm{~mol}^{-1}$, and the experimental data [21] show the following value: $\Delta H_{\mathrm{int}}=-1.77 \mathrm{~kJ} \mathrm{~mol}^{-1}$.

Integral and partial Gibbs energies for Bi-In melts were calculated using the data of our thermodynamic modeling and known equations:

$$
\begin{gathered}
\Delta G_{i}^{\mathrm{E}}=R T \ln \gamma_{i}, \\
\Delta G^{\mathrm{E}}=R T\left(x_{1} \ln \gamma_{1}+x_{2} \ln \gamma_{2}\right),
\end{gathered}
$$

where $x_{1}$ and $x_{2}$ are the molar fractions of $\mathrm{Bi}$ and In, $\gamma_{1}$ and $\gamma_{2}$ are the activity coefficients of Bi and In in the melt.
The concentration dependences of the integral and partial Gibbs energies calculated by the equations (1) and (2) at 600 and $873 \mathrm{~K}$, and literary data [16, 21] are listed in the Table 2. One can see that the values of the partial and integral Gibbs energies are negative. The higher the temperature, the greater are the absolute values of the Gibbs energies.

Minimum values of $\Delta G^{\mathrm{E}}=-1.80 \mathrm{~kJ} \mathrm{~mol}^{-1}$ at $600 \mathrm{~K}$ and $\Delta G^{\mathrm{E}}=-1.99 \mathrm{~kJ} \mathrm{~mol}^{-1}$ at $873 \mathrm{~K}$ correspond to the concentration range close to $x(\operatorname{In})=0.6$. This fact also confirms the existence of associates in the melt. Their total content is maximal in this concentration region.

\section{Conclusions}

As a result of literature survey the four phases in $\mathrm{Bi}$-In system, namely, $\mathrm{BiIn}, \mathrm{Bi}_{3} \mathrm{In}_{5}, \mathrm{BiIn}_{2}$ and $\alpha_{1}-\mathrm{BiIn}_{9}$ were picked out from the phase diagrams. Critical evaluation of thermodynamic properties of these intermetallics was carried out. The obtained information was used to perform thermodynamic modeling of equilibrium compositions and thermochemical properties of $\mathrm{Bi}-\mathrm{In}$ alloys. The thermodynamic properties were calculated using the ISIP methodology. The concentration and temperature dependences of the components activities, partial and integral characteristics of mixing and also the composition of the melts according to the ISIP model were determined. It was established that the negative deviations from Raoult's law take place. Maximum associate (cluster) concentrations were observed for the components contents which meet the compositions of intermetallics according to the phase diagram. The minimum values of the mixing thermodynamic functions are located in the indium-rich region (within the range of 0.5-0.6 molar fraction of In). A number of intermetallic compounds is detected within this concentration range. This fact allows us to assume the formation of the associates with the compositions close to these intermetallics. 


\section{Acknowledgements}

This work was supported by the Presidium of RAS (Project 12-P-3-1032) and RFBR No.14-03-01126 A.

\section{References}

[1] Prigogine, I., Defay, R.: Chemical Thermodynamics. London, Longmans Green 1954.

[2] Sommer, F.: Z. Metallkunde, 73, 1982, p. 72.

[3] Sommer, F.: Z. Metallkunde, 73, 1982, p. 77.

[4] Wasai, K., Mukai, K.: J. Japan Inst. Metals, 45, 1981, p. 593.

[5] Pelton, A. D., Degterov, S. A., Eriksson, G., Robelin, C., Dessureault, Y.: Met. \& Mat. Trans. B, 31, 2000, p. 651. doi:10.1007/s11663-000-0103-2

[6] Pelton, A. D., Kang, Y.-B.: Int. J. Mat. Res., 98, 2007, p. 907. doi:10.3139/146.101554

[7] Bhatia, A. B., Singh, R. N.: Phys. Chem. Liq., 11, 1982, p. 285. doi:10.1080/00319108208080752

[8] Novakovic, R., Ricci, E., Giuranno, D., Lanata, T., Amore, S.: Calphad, 33, 2009, p. 69. doi:10.1016/j.calphad.2008.09.002

[9] Ashcroft, N. W., Stroud, D.: Solid State Phys., 33, 1978, p. 81. doi:10.1016/S0081-1947(08)60468-3

[10] Lai, S. K., Matsuura, M., Wang, S.: J. Phys. F., 13, 1983. p. 2033. doi:10.1088/0305-4608/13/10/014

[11] Ryltsev, R., Kulikova, T., Mayorova, A., Shunyaev, K., Zinigrad, M.: Melts, 6, 2012, p. 20 (in Russian).

[12] Kulikova, T. V., Maiorova, A. V., Bykov, V. A, Shunyaev, K. Yu.: Russian Journal of Physical Chemistry A, 86, 2012, p. 1185.

[14] Hultgren, R., Desai, P. D., Hawkins, D. T., Gleiser, M., Kelly, K.: Selected Values of Thermodynamics Properties of Binary Alloys. Metals Park, ASM International 1973.

[15] Wittig, F. E., Muller, E.: Z. für Phys. Chem., 21, 1959, p. 47. doi:10.1524/zpch.1959.21.1_2.047
[16] Gregorczyk, Z., Stawarz, L., Jurzyk, E.: J. Chem. Thermodyn., 13, 1981, p. 647. doi:10.1016/0021-9614(81)90035-5

[17] Hansen, M., Anderko, K.: Constitution of Binary Alloys. 2nd Edition. New York, McGraw-Hill Book Comp. 1958.

[18] Samsonov, G. V., Abdusalyamova, M. N., Chernogorenko, V. B.: Bismuthides. Kiev, Naukova Dumka 1977 (in Russian).

[19] Giessen, B. C., Morris, M., Grant, N. J.: Trans. Met. Soc. AIME, 239, 1967, p. 883.

[20] Currie, P. D., Finlayson, T. R., Smith, T. F.: J. LessCommon Met., 62, 1978, p. 13. doi:10.1016/0022-5088(78)90012-7

[21] Okamoto, H.: Bismuth-Indium Binary Alloy Phase Diagram. 2nd edition. Material Parks, ASM International 1990.

[22] Boom, R., Vendel, P. C. M, de Boer, F. R.: Acta Metall., 21, 1973, p. 807. doi:10.1016/0001-6160(73)90045-X

[23] Chevalier, P.-Y.: Calphad, 12, 1988, p. 383. doi:10.1016/0364-5916(88)90040-5

[24] Singh, H. P.: Scr. Metall., 6, 1972, p. 519. doi:10.1016/0036-9748(72)90039-7

[25] Robinson, P. M, Bever, M. B.: Trans. AIME, 233, 1965, p. 1908.

[26] Blachnik, R., Schneider, A.: Zeitschrift für Anorganische und Allgemeine Chemie, 372, 1970, p. 314. doi:10.1002/zaac.19703720308

[27] Moiseev, G., Vyatkin, G.: Thermodynamic Modeling in Inorganic Systems. Chelyabinsk, UrGU 1999 (in Russian).

[28] Moiseev, G. K., Vatolin, N. A., Ilyin, N. I., Zaitseva, S. I.: Doklady RAS, 337, 1994, p. 775 (in Russian).

[29] Chirulli, G., Ferro, D., Piacente, V.: Journal of Materials Science Letters, 3, 1984, p. 381. doi:10.1007/BF00724372

[30] Yang, H. W., Tao, D. P., Zhou, Z. H.: Acta Metall. Sin. (Engl. Lett.), 21, 2008, p. 336. 